\title{
Brain sweet brain \\ Importance of sugars for the cerebral microenvironment and tumor development
}

\author{
Thereza Quirico-Santos', Clovis O. Fonseca², Jussara Lagrota-Candido ${ }^{3}$
}

\begin{abstract}
The extracellular matrix (ECM) in the brain tissue is a complex network of glycoproteins and proteoglycans that fills the intercellular space serving as scaffolding to provide structural framework for the tissue and regulate the behavior of cells via specific receptors - integrins. There is enormous structural diversity among proteoglycans due to variation in the core protein, the number of glycosaminoglycans chains, the extent and position of sulfation. The lectican family of proteoglycans interacts with growth factors, hyaluronan and tenascin forming a complex structure that regulates neuronal plasticity and ion homeostasis around highly active neurons. In this review, we will discuss the latest insights into the roles of brain glycoproteins as modulators of cell adhesion, migration, neurite outgrowth and glial tumor invasion.
\end{abstract}

Key words: glycoproteins, extracellular matrix, brain microenvironment, glioma.

\section{Cérebro doce cérebro: importância dos açúcares para o microambiente cerebral e o desenvolvimento tumoral}

\section{RESUMO}

A matriz extracelular (ECM) no tecido cerebral é formada por uma rede complexa de glicoproteínas e proteoglicanas que preenchem o espaço intercelular participando como estrutura de sustentação do arcabouço tecidual regulando a função celular por interações com receptores específicos - as integrinas. Existe enorme diversidade estrutural entre as proteoglicanas, devido à variação na proteína central (core), à quantidade de cadeias de glicosaminoglicanas, ao grau e posição de grupamentos sulfato na molécula. As proteoglicanas lecticanas interagem com fatores de crescimento, com hialuronana e tenascina formando uma estrutura complexa regulando a homeostase de íons e a plasticidade neuronal. Neste artigo de revisão serão apresentados dados relevantes da literatura sobre o papel das glicoproteínas no microambiente do tecido cerebral, como moduladores da neuritogênese, da adesão, migração celular e invasividade de células tumorais de origem glial. Palavras-chave: glicoproteínas, matriz extracelular, microambiente cerebral, glioma.

\section{Correspondence}

Thereza Quirico-Santos Laboratory of Cellular Pathology Department of Cellular and

Molecular Biology Institute of Biology Fluminense Federal University Outeiro São João Batista s/n 24020-141 Niterói RJ - Brasil

E-mail: tquirico@vm.uff.br

Received 9 April 2010

Received in final form 12 April 2010

Accepted 20 April 2010
The brain presents restricted well-defined stromal space. A large proportion of the brain volume consists of space between neurons and astrocytic processes filled with extracellular matrix (ECM) components that influence neuronal communication and regulate plastic changes protecting neurons and synapses against damage. The brain ECM is unique in composition and organization as it contains rel- atively small amounts of fibrous proteins but high amounts of carbohydrates either bound to proteins forming proteoglycans (PG) or unbound in the form of hyaluronan which are abundant in the brain parenchyma. Conversely, the cerebral vascular basement membrane surrounding blood vessels contains type-IV and typeV-collagens, fibronectin, laminin, vitronectin and heparan-sulfate proteoglycans ${ }^{1}$.

'Laboratory of Cellular Pathology, Department of Cellular and Molecular Biology, Institute of Biology, Fluminense Federal University, Niterói RJ, Brasil; ${ }^{2}$ Department of General and Specialized Surgery; Clinical Research Unit, Antonio Pedro University Hospital, Niterói RJ, Brasil; ${ }^{3}$ Laboratory of Immunopathology, Department of Immunobiology, Institute of Biology, Fluminense Federal University, Niterói RJ, Brasil. 
Hyaluronan or hyaluronic acid is a multifunctional glycosaminoglycan (GAG) synthesized as a large negatively charged linear polymer by distinct hyaluronan synthas$\mathrm{es}^{2}$. Hyaluronan organizes the structure of the pericelllular matrix by assuming variety of conformations, from extended chains to condensed rods, helical coils, networks and stacks ${ }^{3}$. The binding to specific cell surface receptors such as CD44 or RHAMM (receptor for hyaluronic acid mediated motility) ${ }^{4}$ activates pathways that regulate biological properties of the ECM and tissue function such as cell proliferation, differentiation, adhesion and motility, transport of ions, solutes and nutrients. A synergistic interaction of growth factors (FGF, VEGF, PDGF) with high-affinity receptors stimulates endothelial cell proliferation, vasculogenesis and angiogenesis which is essential for maintenance of stromal integrity during CNS development ${ }^{5,6}$. However, cells that express high affinity receptors but lack surface heparan sulfate proteoglycans do not respond to the stimulus.

PGs are formed by a core protein with one or more covalently attached GAG chain conferring a high negatively charged molecule owing to the presence of acidic sugar residues and/or modification by sulfate groups. The diversity of PG is dependent on differential expression of genes encoding core proteins, alternative splicing and variations in the length and types of GAG side chains. Glypicans and syndecans constitute two families of transmembrane proteoglycans carrying heparan sulfate side chains present in large amounts in the central nervous system. PGs serve as cofactors and regulators of growth factors influencing cell adhesion, neurite outgrowth, ECM assembly and tumor cell invasion ${ }^{7,8}$. Heparan sulfate proteoglycans affect directly the activity and aggregation of AMPA receptors, and also interfere with learning and memory by induction or maintenance of long-term potentiation (LTP). Chondroitin sulfate PG (CSPG) is expressed in regions of the developing brain influencing axonal sprouting and stabilization of synapses, is also abundant postnatally in the cerebellum and hippocampus but decreases markedly after birth ${ }^{8,9}$. In the mature brain, CSPG is present in the cytoplasm of neurons and astrocytes, and in myelinated and non-myelinated axon fibres, but not in oligodendrocytes ${ }^{1}$.

Lecticans are a family of chondroitin sulfate proteoglycans that contain lectin and hyaluronic acid-binding domains acting as linkers to ECM components. Molecular cloning identified four lecticans: aggrecan, versican, neurocan and brevican. Glial cells from central and peripheral nervous system, neural stem cells and neural cells derived from embryonic stem cells produce versican ${ }^{10}$. Versican is up-regulated following injury and at least in vitro exhibit inhibitory effects upon neurite outgrowth. Neurocan is expressed in boundaries of active axonal growth during development and especially under pathological conditions at the lesion site ${ }^{11}$.

Hyaluronan is widely distributed in gray and white matter but aggrecan- and link protein show characteristic regional distribution patterns in perineuronal nets

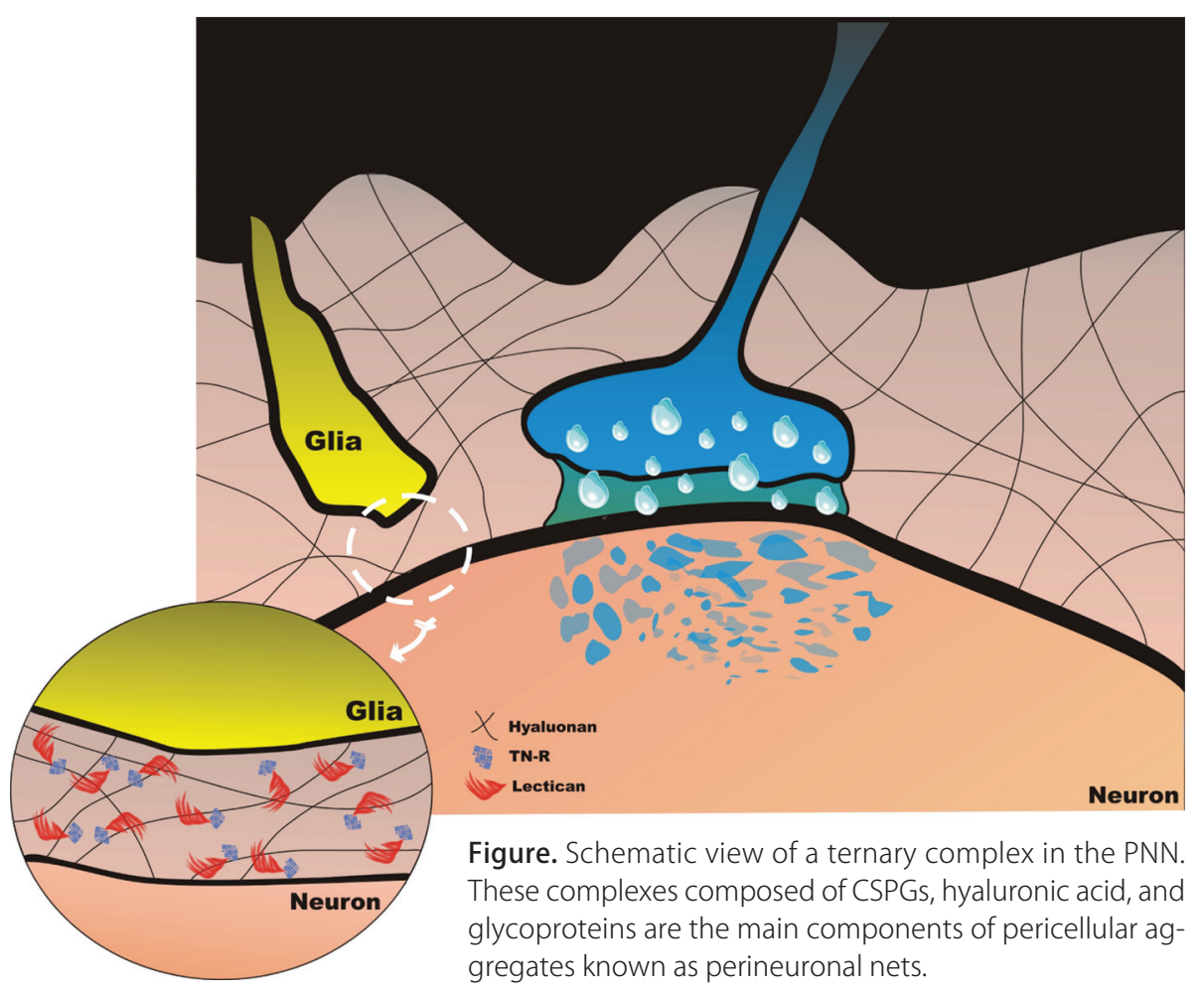


(PNNs) and axonal coats (ACs) encapsulating preterminal fibers and synaptic boutons adapted to the fast processing of sensorimotor activities ${ }^{6,12}$. PNNs are associated with GABAergic projection neurons in the external and internal division of the globus pallidus, the lateral and reticular part of the substantia nigra, and subpopulations of striatal and thalamic inhibitory interneurons expressing parvalbumin, a calcium-binding protein ${ }^{13}$. A dense network of ACs is characteristic of the posterior lateral cell groups (nigrosome 1) of the compact substantia nigra (Figure). PNNs are composed of chondroitin sulfate PGs versican, brevican, neurocan, cat-301 antigen (aggrecan), phosphacan (DSD-1-PG), HA, tenascin-C, tenascin- $\mathrm{R}$, and link proteins forming a structure involved in the regulation of neuronal plasticity and ion homeostasis around highly active neurons ${ }^{7}$. The HA-lecticans-tenascin complex on neuronal surfaces forms a repulsive barrier against axon and dendrites interaction and also development of new synaptic contacts, especially during postnatal life ${ }^{6}$. Neurons ensheathed by PNNs are less frequently affected by lipofuscin accumulation both in normalaged and Alzheimer's brain tissue ${ }^{6,14}$. Aging and protein aggregation cause deposition of heparan and chondroitin sulfate PGs resulting in loss of protective PNNs and increased susceptibility to cell death. Dying neurons induce inflammation, ECM degradation through proteolytic activity of matrix metalloproteinases and tissue plasminogen activator (tPA), induction of chemotaxis and microglial activation with local cytokine production that amplify neuroinflammation and neuronal death ${ }^{6,15}$.

Galectins and collectins (mannose-binding lectins and surfactant proteins) are endogenous glycan-binding proteins present both inside and outside cells, expressing conserved carbohydrate recognition domain (CRD) with a canonical amino acid sequence and affinity for beta galactosides ${ }^{16,17}$. Galectins and its cellular and extracellular ligands mediating cell-to-cell and cell-to-matrix interactions are master regulators of innate and adaptive immune responses under physiological or pathological conditions ${ }^{16,18}$. The extracellular release of galectins is different from classic secretory pathways, as adhesion molecules present high affinity for ECM components and integrins ( $\alpha 1 \beta 7 / \alpha 7 \beta 1$; CD11b/CD18) important for stabilization of lectin activity, but free Gal molecules are rapidly oxidized and inactivated in the nonreducing extracellular environment ${ }^{18,19}$

Gal-1 is widely distributed in the central and peripheral nervous systems (pia mater, the choroid plexus, the pineal gland, reactive astrocytic and Schwann cells) participating during development in the formation of neural and non-neuronal network. In normal brain tissue, Gal-3 interacts with several neural-tissue-derived glycoproteins (neuronal adhesive glycoprotein L1; N-CAM; myelin-as- sociated glycoprotein), but degree of Gal-3 oligomerization may enhance or inhibit cell adhesion due to steric hindrance. In normal brain tissue Gal3 is highly expressed in normal astrocytes and endothelial cells but completely negative in neurons, oligodendrocytes and microglia ${ }^{20}$.

\section{Not so sweet: the role of sugars in tumorigenesis}

The invasiveness of glioma cells, a major cause of mortality in malignant brain tumors, is greatly influenced by the cellular microenvironment. Hyaluronan (HA) is present at elevated levels in the matrices of gliomas similarly to the embryonic brain matrix. Aberrant interactions between tumor cells and the ECM allow diffuse infiltration of single tumor cells into the brain parenchyma with cells dividing more rapidly on rigid than on compliant $\mathrm{ECMs}^{21,22}$.

The progression of the malignancy of a tumor is a multistep process that involves cell-cell and cell-ECM adhesion, invasion, migration, and angiogenesis. Primary GBM, commonly overexpress the epidermal growth factor receptor (EGFR) and its ligand-independent mutant EGFRvIII $^{23}$ that activates a number of downstream pathways including PI3K-AKT and RAS-MAPK; induce cell proliferation but inhibits apoptosis. Ras signaling is implicated in gliomagenesis ${ }^{24}$ a process partly depend on the dynamic interplay of carboxy-terminal domain of the Ras proteins recognized by Gal-1, Gal-3 and cGMP phosphodiesterase delta ${ }^{25}$. Expression of K-ras, a brain specific isoform of ras and MAPK pathway leads to enhanced transcription of ECM proteins and cytoskeletal rearrangement thus promoting glioma invasiveness ${ }^{26}$. In addition K-Ras-GTP interaction with Gal3 causes a conformational change in the molecule leading to activation of Raf, PI3K pathways but inhibiting ERK signaling and resistance to apoptosis besides modifying biological functions of the tumor suppressor gene TP53 leading to loss of p53 functionality and chemoresistance $\mathrm{e}^{16,27}$. Hypoxia confers chemo and radioresistance to tumor cells, modulates the unfolded protein response (UPR) during endoplasmic reticulum (ER) stress, triggers p53 accumulation and activation, and acts as potent inducer of Gal-1 and Gal-3 glycosylation, accelerating malignant progression especially of diffuse astrocytic tumors ${ }^{2,28}$.

Gal-1 is involved in several of the steps of malignant progression, mediating tumor cell adhesion to ECM proteins and homotypical cell adhesion and also promoting cell detachment and migration ${ }^{21}$. Gal-1 promotes cell adhesion by increasing crosslinking of glycoproteins (integrins) with carbohydrate moieties of ECM components; increases motility and invasiveness because activates expression of RhoA, protein involved in reorganization of actin cytoskeleton; and the interaction with Ras genes which are frequently mutated in human tumors promote malignant transformation ${ }^{16}$. Gal-1 is a major receptor for 
the carbohydrate portion of the ganglioside GM1 exposed on the surface of human neuroblastoma cells. The pattern and overexpression of Gal-1 in tumors and surrounding tissue is often considered as a sign of malignant progression but the apparent paradoxical effects on cell growth dependent mainly on the cell type, activation status and characteristics of the molecule (monomeric versus dimeric, or intracellular versus extracellular forms ${ }^{20,29}$. In addition, Gal-1 is a soluble inhibitory factor also involved in mechanisms of tumor escape by inducing apoptosis of effector $\mathrm{T}$ cells, inhibiting the Fas death receptor and perforin / granzymes exocytosis pathways used by cytotoxic $\mathrm{T}$ cells to kill tumor cells ${ }^{18,30}$. High serum levels of Gal-1, correlates with aggressiveness of tumors and acquisition of metastatic phenotype and poor prognosis for the patient ${ }^{29,31}$. The level of Gal-3 expression by astrocytes, endothelial cells and macrophages is used to discriminate glioblastoma (GBMs) from anaplastic oligodendroglioma, and pilocytic astrocytoma from diffuse astrocytoma ${ }^{20,32}$. Loss of Gal-3 expression in endothelial cells is associated with glomeruloid endothelial cell proliferation and considered a distinctive feature tumor neovasculature ${ }^{20}$. In contrast, marked expression of Gal-1 occurs under hypoxic conditions associated with necrosis and vascular proliferation, pathological features of the hypercellular zone called pseudopalisades, considered a characteristic formation of malignant infiltrative glioma with poor prognostic ${ }^{18,33}$. The interaction between tumour cells, normal stromal cells and ECM is an essential part of tumor cell invasion and is controlled by different protease systems ${ }^{1}$. The ECM surrounding hypoxic center of pseudopalisades show increased expression of proteolytic enzymes matrix metalloproteinases (MMPs) and the urokinase-dependent plasminogen-activating cascade associated with invasive phenotype, degenerating vessels, and intravascular thrombosis with outward migration of glioma cells ${ }^{33,34}$.

Migrating glioma cells express high levels of V0/V1 versican isoforms that interacts via G3 domain with EGFR and beta-1 integrin activating ERK signaling pathways responsible for tumor promoting effects ${ }^{35,36}$. Oligodendroglioma, all grades of astrocytoma, and glioblastoma cells produce high levels of $\mathrm{BEHAB} /$ brevican, a secreted chondroitin sulfate proteoglycan with a N-terminal hyaluronan-binding domain, that interacts with fibronectin and further enhance proinvasive capacity of glioma cells ${ }^{8}$. Versican-rich in association with hyaluronan, CD44, tenascin and TGF- $\beta 2$ in the pericellular matrix of high-grade glioma, exert an anti-adhesive effect facilitating tumor cell migration and invasiveness. Versican splice by tissue proteases produces isoforms that activate ERK cell signaling, promote imbalance between Smad and MAPK pathways responsible for TGF- $\beta$ tumor promoting effect in high- grade glioma and poor patient survival ${ }^{36,37}$. In addition, abnormal interaction of $\mathrm{CD} 44$ hyaluronan receptor and the epidermal growth factor activates plasminogen cascade and promote anchorage-independent growth and invasiveness, hallmarks of the malignant phenotype'. Chondroitin sulfate proteoglycans associated with hyaluronic acid, tenascins (TN-X, TN-R, TN-C) and link proteins are also up-regulated especially at the infiltrative tumoral edge of gliomas providing pro-invasive signals to the matrix scaffold by allowing cells to detach rapidly. Increased $\mathrm{TN}-\mathrm{C}$ expression in gliomas and accumulation around blood vessels correlate with recurrence and tumor progression from grade II to grade III. Moreover, glioma invasion along myelinated fibre tracts of white matter results in spread of tumor cells through the corpus callosum to the contralateral hemisphere ${ }^{1}$.

In conclusion, the matrix laid down by cells is a complex molecular scaffolding source of growth factors and proteases that provide survival and danger signals that activate pathways influencing tissue microenvironment and development of neurological diseases. The role of the lecticans as inhibitors of motility in the adult brain tissue contrasts with the proinvasive role in highly aggressive brain tumors and invasion into brain parenchyma.

\section{REFERENCES}

1. Rao JS. Molecular mechanisms of glioma invasiveness: the role of proteases. Nat Rev Cancer 2003;3:489-501.

2. Park JB, Kwak HJ, Lee SH. Role of hyaluronan in glioma invasion. Cell Adh Migr 2008;2:202-207.

3. Evanko SP, Tammi MI, Tammi RH, Wight TN. Hyaluronan-dependent pericellular matrix. Adv Drug Deliv Rev 2007;59:1351-1365.

4. Murphy JF, Lennon F, Steele C, Kelleher D, Fitzgerald D, Long AC. Engagement of CD44 modulates cyclooxygenase induction, VEGF generation, and proliferation in human vascular endothelial cells. FASEB J 2005;19:446-448.

5. Peattie RA, Nayate AP, Firpo MA, Shelby J, Fisher RJ, Prestwich GD. Stimulation of in vivo angiogenesis by cytokine-loaded hyaluronic acid hydrogel implants. Biomaterials 2004;25:2789-2798.

6. Bonneh-Barkay D, Wiley CA. Brain extracellular matrix in neurodegeneration. Brain Pathol 2009;19:573-585.

7. Galtrey CM, Fawcett JW. The role of chondroitin sulfate proteoglycans in regeneration and plasticity in the central nervous system. Brain Res Rev 2007;54:1-18.

8. Viapiano MS, Matthews RT. From barriers to bridges: chondroitin sulfate proteoglycans in neuropathology. Trends Mol Med 2006;12:488-496.

9. $\operatorname{Sim} \mathrm{H}, \mathrm{Hu} \mathrm{B}$, Viapiano MS. Reduced expression of the hyaluronan and proteoglycan link proteins in malignant gliomas. J Biol Chem 2009;284: 26547-26556.

10. Abaskharoun M, Bellemare M, Lau E, Margolis RU. Expression of hyaluronan and the hyaluronan-binding proteoglycans neurocan, aggrecan, and versican by neural stem cells and neural cells derived from embryonic stem cells. Brain Research 2010;23:6-15.

11. Buss A, Pech K, Kakulas BA, et al. NG2 and phosphacan are present in the astroglial scar after human traumatic spinal cord injury. BMC Neurol 2009; 9:32-47.

12. Bruckner G, Morawski M, Arendt T. Aggrecan-based extracellular matrix is an integral part of the human basal ganglia circuit. Neuroscience 2008;151:489-504

13. Pantazopoulos H, Murray EA, Berretta S. Total number, distribution, and phenotype of cells expressing chondroitin sulfate proteoglycans in the normal human amygdala. Brain Res 2008;1207:84-95.

14. Morawski M, Bruckner MK, Riederer P, Bruckner G, Arendt T. Perineuronal 
nets potentially protect against oxidative stress. Exp Neurol 2004;188: 309-315.

15. Candelario-Jalil E, Yang Y, Rosenberg GA. Diverse roles of matrix metalloproteinases and tissue inhibitors of metalloproteinases in neuroinflammation and cerebral ischemia. Neuroscience 2009;158:983-994.

16. Camby I, Le Mercier M, Lefranc F, Kiss R. Galectin-1: a small protein with major functions. Glycobiology 2006;16:137R-157R.

17. Toscano MA, llarregui JM, Bianco GA, et al. Dissecting the pathophysiologic role of endogenous lectins: glycan-binding proteins with cytokine-like activity? Cytokine Growth Factor Rev 2007;18:57-71.

18. Albesiano E, Han JE, Lim M. Mechanisms of local immunoresistance in glioma. Neurosurg Clin N Am 2010;21:17-29.

19. Jung $\mathrm{T}-\mathrm{Y}$, Jung $\mathrm{S}$, Ryu $\mathrm{H}-\mathrm{H}$, et al. Role of galectin-1 in migration and invasion of human glioblastoma multiforme cell lines. J Neurosurg 2008;109:273-284.

20. Park S-H, Min HS, Kim B, Myung J, Paek SH. Galectin-3: A useful biomarker for differential diagnosis of brain tumors. Neuropathology 2008;28:497-506.

21. Ulrich TA, de Juan Pardo EM, Kumar S. The mechanical rigidity of the extracellular matrix regulates the structure, motility, and proliferation of glioma cells. Cancer Res 2009;69:4167-4174.

22. Sarkar S, Yong VW. Reduction of protein kinase $C$ delta attenuates tenascin- $C$ stimulated glioma invasion in three-dimensional matrix. Carcinogenesis 2010;31:311-317.

23. Heimberger $A B$, Hlatky R, Suki $D$, et al. Prognostic effect of epidermal growth factor receptor and EGFRvIll in glioblastoma multiforme patients. Clin Cancer Res 2005;11:1462-1466.

24. Goldberg L, Kloog Y. A Ras inhibitor tilts the balance between Rac and Rho and blocks phosphatidylinositol 3-kinase-dependent glioblastoma cell migration. Cancer Res 2006;66:11709-11717.

25. Ashery $U$, Yizhar $O$, Rotblat B, et al. Spatiotemporal organization of Ras signaling: rasosomes and the galectin switch. Cell Mol Neurobiol 2006;26: 471-495.

26. Nickl-Jockschat T, Arslan F, Doerfelt A, Bogdahn U, Bosserhoff A, Hau P. An imbalance between Smad and MAPK pathways is responsible for TGF-beta tumor promoting effects in high-grade gliomas. Int J Oncol 2007:30:499-507.
27. Strano S, Dell'Orso S, Di Agostino S, Fontemaggi G, Sacchi A, Blandino G. Mutant p53: an oncogenic transcription factor. Oncogene 2007;26: 2212-2219.

28. Le Mercier M, Mathieu $V$, Haibe-Kains B, et al. Knocking down galectin 1 in human hs683 glioblastoma cells impairs both angiogenesis and endoplasmic reticulum stress responses. J Neuropathol Exp Neurol 2008;67:456-469.

29. Kovács-Sólyom F, Blaskó A, Fajka-Boja R, et al. Mechanism of tumor cellinduced T-cell apoptosis mediated by galectin-1. Immunology Letters 2010;127:108-118

30. Liu FT, Rabinovich GA. Galectins as modulators of tumour progression. Nat Rev Cancer 2005:5:29-41.

31. Saussez S, Lorfevre F, Lequeux T, et al. The determination of the levels of circulating galectin- 1 and -3 in HNSCC patients could be used to monitor tumor progression and/or responses to therapy. Oral Oncol 2008;44:86-93.

32. Neder L, Marie SK, Carlotti Jr. CG, et al. Galectin-3 as an immunohistochemical tool to distinguish pilocytic astrocytomas from diffuse astrocytomas, and glioblastomas from anaplastic oligodendrogliomas. Brain Pathol 2004; 14:399-405.

33. Brat DJ, Castellano-Sanchez AA, Hunter SB, et al. Pseudopalisades in glioblastoma are hypoxic, express extracellular matrix proteases, and are formed by an actively migrating cell population. Cancer Res 2004;64: 920-927.

34. Gondi CS, Dinh DH, Gujrati M, Rao JS. Simultaneous downregulation of UPAR and MMP-9 induces overexpression of the FADD-associated protein RIP and activates caspase 9-mediated apoptosis in gliomas. Int J Oncol 2008:33:783-790

35. Wu Y, Chen L, Zheng PS, Yang BB. Beta 1-Integrin-mediated glioma cell adhesion and free radical-induced apoptosis are regulated by binding to a Cterminal domain of PG-M/versican. J Biol Chem 2002;277:12294-12301.

36. Ricciardelli C, Sakko AJ, Ween MP, Russell DL, Horsfall DJ. The biological role and regulation of versican levels in cancer. Cancer Metastasis Rev 2009; 28:233-245.

37. Liu S, Tian Z, Yin F, et al. Expression and functional roles of Smad1 and BMPR-IB in glioma development. Cancer Invest 2009;27:734-740. 